\title{
LA ELABORACIÓN DE UN SERMÓN EXPOSITIVO
}

Jud Lake

jslake@southern.edu Sourthern Adventist University

96 Resumen| El presente artículo aborda la metodología para elaborar un sermón expositivo. A través de una lectura amena y profunda, el autor describe los pasos para ser tanto profundos como explícitos a la hora de elaborar y presentar la Palabra de Dios en un sermón. El sermón expositivo es la mejor opción para un predicador que quiera mostrar la voluntad de Dios, desarrollada en las Escrituras.

Palabras clave: Predicación expositiva, exégesis, sintaxis, homilética. 


\section{EXPOSITORY SERMON PREPARATION}

This article discusses the methodology to develop an expository sermon. Through an entertaining and profound reading, the author describes the steps to be both profound and explicit when it comes to preparing and presenting the Word of God in a sermon. The expository sermon is the best choice for a preacher who wants to show the will of God, developed in Scripture.

Keywords: Preaching, expository, exegetical, syntax, homiletics. 


\section{Introducción}

Haddon Robinson, un reconocido predicador, describe la preparación de un sermón como un "proceso dinámico" que consiste en "conocimiento, imaginación y sensibilidad espiritual - ninguno de los cuales proviene simplemente de seguir instrucciones". Sin embargo, "el conocimiento experimentado, del abordaje del texto bíblico, puede producir confianza y contribuye a un uso más eficiente del tiempo y de la energía". ${ }^{1}$ Con esta premisa en mente, propongo el siguiente enfoque de diecisiete etapas para preparar sermones expositivos. Es muy probable que predicadores experimentados puedan fusionar y/o mezclar algunas de las etapas; no obstante, cada una de las etapas es un ingrediente vital para el proceso. Las primeras diez etapas se centran en el análisis exegético, las últimas siete se enfocan en la síntesis de homilética. Todo el proceso debe tomar entre 12 a 20

${ }^{1}$ Haddon Robinson, Biblical Preaching: The Development and Delivery of Expository Messages, (Grand Rapids: Baker Academic, 2001), 53. horas, dependiendo de la experiencia del expositor.

\section{Análisis exegético}

Tres preguntas importantes deben realizarse durante el análisis exegético de principio a fin: 1) ¿Quién es el autor? La respuesta a esta pregunta es la idea principal del texto, pues es una referencia concisa sobre cómo se entendió originalmente el texto. Esta idea central o exegética es encontrada a menudo en un solo punto en el texto, a veces se intercala entre dos ideas relacionadas, o, a veces, se encuentran en ideas recurrentes. 2) ¿Por qué lo está diciendo el autor? La respuesta a esta pregunta revela el propósito del autor. Así como cada pasaje de la Escritura tiene una idea principal, también tiene un propósito concreto.

Por lo tanto, plantearse estas preguntas a través del estudio; ¿por qué el autor escribió esto? y ¿qué efecto esperaba tener en sus lectores?, se constituyen en la objetivo del autor al escribir determinado texto. No obstante, el significado total del texto a menudo será 
entendido buscando a lo largo de todo el contexto literario. En ese sentido, la tercera pregunta es: 3 ) ¿cómo el autor bíblico lo está diciendo (el versículo)? La respuesta a esta pregunta es el género literario particular del pasaje, es decir, la estructura literaria que el autor está utilizando para comunicar su idea. En este punto la atención se centra en la determinación de la estructura retórica del pasaje, puntualizar cuál es el tema en el esquema exegético.

Con estas tres preguntas en mente, el predicador debe proseguir con las diez etapas de análisis exegético:

Etapa 1: Orar por la dirección del Espíritu Santo. Es importante destacar desde el principio de la preparación del sermón que el expositor busque la presencia y la ayuda del Espíritu de Dios.

Etapa 2: Determinar la unidad textual. Definir los parámetros textuales según el contexto literario del pasaje. Si el texto es parte de una serie expositiva sistemática, pueden utilizarse los parámetros ya establecidos de un estudio previo.
Etapa 3: Haz un resumen del pasaje. Léalo con oración y meditabundo en numerosas ocasiones. Obtener un sentido de su flujo. Tome notas provisionales de ideas que vienen o asuntos que necesitan ser explorados.

Etapa 4: Determinar el género o tipo de literatura del pasaje. Las opciones posibles son: narrativa, poesía, sapiencial, profecía, evangelios, parábola, epístola y apocalíptica. Una vez identificado el género literario del pasaje, es necesario aplicar las normas especiales para cada género que serán ampliadas durante la etapa de siete a continuación.

Etapa 5: Analizar el contexto literario del pasaje. Esta etapa consiste en leer y estudiar el contexto más amplio, se remite a todo el libro, capítulo o capítulos, el contexto inmediato, párrafos o versos que rodean el pasaje.

Etapa 6: Analizar el contexto histórico y/o cultural del pasaje. Para este cometido es necesario utilizar las siguientes herramientas de investigación: diccionarios bíblicos y enciclopedias. Estudios especializados sobre el contexto 
histórico y cultural de la Biblia $y$, por último, es recomendable revisar los comentarios que los eruditos realizan de cada libro de la Biblia. ${ }^{2}$ La información que se debe recabar en las fuentes mencionadas son: autor, destinatarios, la fecha, la situación, la cultura, la política y la geografía en la que se compuso y tomó lugar el pasaje de estudio.

Etapa 7: Analizar el pasaje a detalle. La gramática y la sintaxis del pasaje, incluyendo especialmente las palabras significativas ${ }^{3}$ en función del género literario.

100 Estas deben ser analizadas con las siguientes herramientas de investigación apropiadas para el predicador: textos hebreo, griego o arameo; léxicos, concordancias, gramáticas y libros de estudio de

\footnotetext{
${ }^{2}$ Ver Tim Crosby, "eTreasures: Seven Ways to Enhance Your Ministry through the Internet", Ministry (2004): 5-6, 27; Lee J. Gugliotto, Handbook for Bible Study (Hagerstown: Review and Herald Publishing Association, 1995).

${ }^{3}$ Las palabras significativas o importantes son aquellas palabras que sino estuvieran en el pasaje, este carecería de sentido. Es importante identificarlas y darles el tratamiento exegético que se menciona en el paso siete.
}

palabras. En este punto, es muy útil un diagrama de flujo ${ }^{4}$ del pasaje. El resultado final de esta etapa es una articulación de la idea y propósito exegético del pasaje.

Etapa 8: Analizar el contexto teológico del pasaje. Esta etapa consiste en estudiar el pasaje en su contexto canónico más amplio, o sea en toda la Biblia. Es necesario preguntarnos ¿cómo se aplica el versículo de estudio en más versículos de las Escrituras? ¿Cuáles son los antecedentes teológicos del versículo de estudio? En este punto, es importante tener en cuenta cómo el texto se refiere a Cristo. ¿Qué dice acerca de Él?

Etapa 9: Consulte los comentarios ${ }^{5}$ sobre el pasaje. Tome nota

${ }^{4}$ Un diagrama de flujo es la forma más útil de analizar a nivel estructural una oración. Consiste en describir gráficamente por sangría y subordinación la relación entre palabras y cláusulas en un pasaje. Ver Gordon D. Fee, Exégesis del Nuevo Testamento: Manual para estudiantes y pastores, trad., David Gómez R. (Miami: Editorial Vida, 1992), 54.

${ }^{5}$ Un comentario es un libro (ya sea una obra única o un libro que forme parte de una colección) que un autor destacado en el área escribe, básicamente comentando y resolviendo los temas 
de las ideas relevantes que podrían hacer algún cambio en sus conclusiones que sacó hasta este punto. En general, lo mejor es estudiar los comentarios después de completar su propio trabajo exegético.

Etapa 10: Resuma sus hallazgos. Escriba la idea exegética, propósito exegético y el esquema estructural del pasaje. Estos tres elementos de análisis exegético serán muy relevantes al momento de comenzar el proceso de la síntesis de homilética. La idea exegética se convertirá en la idea homilética, el propósito exegético se convertirá en el objetivo del sermón, y el diagrama estructural del texto se convertirá en el esquema homilético que conectará el texto con la congregación.

\section{Síntesis homilética}

La síntesis homilética traduce el análisis exegético al lenguaje

de controversia de un libro de la Biblia. Dentro de la Iglesia Adventista del Séptimo Día, por ejemplo, existe una colección de comentarios llamado Comentario bíblico Adventista del 7 mo Día. ed., Francis Nichol. trad., Víctor Ampuero (Buenos Aires: Asociación Casa Editora Sudamericana, 1996). popular y contemporáneo de los oyentes. Como tal, transforma los datos exegéticos en un patrón organizado, con divisiones y un enfoque, ritmo, simetría, movimiento y clímax. Así como en la parte exegética, el expositor debe pedir que el mismo Espíritu Santo guíe el proceso de convertir las notas exegéticas en la síntesis de homilética (Jn 14:26).

Una vez completada el análisis exegético - la parte fundacional - en las etapas 1 al 10; a continuación, en las etapas 11 a 17 , se completará el proceso de preparación del sermón expositivo.

Etapa 11: Traducir la idea exegética del texto en la idea homilética del sermón. Durante esta etapa, el predicador transforma la idea exegética del texto en "la más exacta frase memorable posible". ${ }^{6}$ Esta frase es una declaración de la verdad universal del pasaje en términos relevantes para su público particular. Todo el sermón se construye alrededor de esta idea homilética, pues responde a la pregunta, ¿qué estoy diciendo en este sermón?

${ }^{6}$ Robinson, 103. 
Etapa 12: Traducir el propósito exegético en el propósito homilético. La cuestión aquí es escribir el propósito del sermón, en el marco de su propósito exegético. Por lo tanto, solo se tiene que responder a la pregunta: a la luz de este fin exegético, ¿qué desea Dios llevar a cabo a través de este sermón en los oyentes de hoy? La respuesta a esta pregunta es lo que se espera que los oyentes hagan como resultado de escuchar el sermón.

A su vez, esta declaración está relacionada a una acción moral, 102 por lo que influye en la forma del sermón y proporciona orientación en la aplicación y la conclusión. Responde a la pregunta más grande, ¿por qué estoy predicando este sermón?

Etapa 13: Decida la estructura del sermón con base en el esquema exegético y proponga un esquema. La forma o estructura del sermón depende de dos factores: 1) el género literario, pues este refleja en sí mismo una estructura exegética y 2) el propósito del sermón. Sobre la base de estos dos factores, el predicador decidirá cómo estructurar el sermón, de modo que se adapte al texto y al propósito de la mejor manera.

La forma inductivo-deductivo comienza con las partes y se abre camino hacia la idea homilética en el medio del sermón y luego lo divide en partes específicas para el resto del sermón (movimiento de piezas hacia el todo y del todo hacia las partes). Bajo estas perspectivas, los sermones inductivos son la forma narrativa popular que, básicamente, cuenta la historia bíblica de una manera relevante y significativa. Como puede notarse, hay muchos tipos de formas de sermones disponibles para el expositor que cautivará la atención del público y que reflejarán, con precisión, el contenido de Escritura. ${ }^{?}$ Finalmente, la forma del sermón responde a la pregunta, "¿Cómo voy a predicar este sermón?"

Etapa 14: Ampliar el bosquejo del sermón con material bibliográfico de apoyo. Algunos predicado-

${ }^{7}$ Véase. Harold T. Bryson, Expository Preaching: The Art of Preaching Through a Book of the Bible (Nashville: Broadman and Holman, 1995), 339-372; and Donald L. Hamilton, Homiletical Handbook (Nashville: Broadman, 1992), 32-116. 
res $\left(y\right.$ homiletas $\left.{ }^{8}\right)$ han comparado el bosquejo del sermón a una estructura de pensamiento. Así como los huesos de una persona están cubiertas de piel y carne, también los huesos (bosquejo) de un sermón deben cubrirse con la piel y la carne de material de apoyo. El material de apoyo da cuerpo a cada división principal del sermón (esto se aplica a cualquier forma deductiva, inductiva, narrativa, etc.).

El material bibliográfico proporciona apoyo amplificando cada pensamiento en relación con la idea principal. Sin el material de apoyo integrado activamente en el sermón expositivo, este puede llegar a ser tedioso, aburrido, e incluso sin vida. Pero cuando se mezclan adecuadamente en el sermón expositivo con el material de apoyo se sumará la comprensión, la didáctica, el interés, el entusiasmo, la relevancia y el humor. Si bien existen numerosos tipos de material de apoyo para los sermo-

${ }^{8}$ Un homileta es aquella persona que se es conocedor de la dinámica de la elaboración de un sermón. Un homileta no siempre es un predicador, y viceversa. nes expositivos, los cuatro básicos son la explicación, la ilustración, la aplicación, y la narración.

Etapa 15: Preparar la introducción y la conclusión. Una vez que el cuerpo sermón es completado, es el momento para pensar sobre cómo introducir y concluir el sermón. Estos dos componentes son extremadamente importantes para el sermón expositivo y deben recibir una gran atención.

Etapa 16: Producir un manuscrito del sermón. La mayoría de homiletas recomiendan que los predicadores, especialmente los novatos, escriban sus sermones en su totalidad. La ventaja de esto es la claridad conceptual respecto del sermón a ser predicado. Un manuscrito permite al expositor ver el sermón en su conjunto y así descubrir los pensamientos inconexos o piezas fuera de lugar. Esta descripción detallada debe ser mecanografiada o escrita. Sin embargo, la mayor ventaja de poseer un manuscrito del sermón es prevenir el encuentro de la poca claridad o relevancia del sermón en un repaso previo que hacer este descubrimiento en el púlpito. 
Etapa 17: Ensaya el sermón con el fin de interiorizarlo. Lea el manuscrito sermón en oración y con cuidado; haga un simulacro en voz alta, permaneciendo alerta ante los posibles problemas, para hacer las correcciones necesarias. A continuación, convierta el manuscrito en notas de predicación. Estas notas deben contener solo el material suficiente para estimular la memoria durante el sermón. Finalmente ensaya nuevamente el sermón con este último material de uso mnemotécnico, esto lo familiarizará por completo con el sermón, a fin que pueda ser entregado con la mayor libertad posible. El público de hoy no tolera, en absoluto, a un predicador atado a sus notas, pues la conexión con los oyentes es imprescindible.

\section{Conclusión}

Si alguna vez hubo un tiempo para que los predicadores Adventistas del Séptimo Día practiquen la predicación expositiva, es ahora. Comentando el encargo de Pablo de "predicar la palabra" (2 Tm 4: 1-2), Elena G. de White escribió: "En estas palabras directas y enfáticas se establece el plan del deber del ministro de Cristo. Es 'predicar la palabra, no las opiniones y tradiciones de los hombres, no fábulas agradables o historias sensacionalistas, para promover el lujo y excitar las emociones'. No se trata de exaltarse a sí mismos; sino que, como estando en la presencia de Dios, presentarse delante de un mundo moribundo y predicar la Palabra... el ministro debe hablar con sinceridad y seriedad profunda, como la voz de Dios exponer las Sagradas Escrituras" (GW, 147). iQue todos los que predican se esfuercen en seguir este consejo! 